\title{
AN EXPERIMENTAL STUDY ON ADVANCED LANE CHANGING SIGNAL ASSIST TECHNOLOGY WITH SMART HELMET
}

\author{
SANA NAZ ${ }^{1}$, SADIA AZAM ${ }^{2} \&$ DR. NADEEM AHMED AWAN ${ }^{3}$ \\ ${ }^{1}$ Student, NED University of Engineering and Technology, Karachi \\ ${ }^{2}$ Scholar, University of Verona, Italy \\ ${ }^{3}$ Professor Faculty of Management Sciences, Foundation University Islamabad
}

\begin{abstract}
Nowadays accidents are an increasing concern all over the world. In present scenario accidents are happening due to the factors of improper implementation and usage of helmets while driving Un-Prediction of other vehicle motions, utilizing low-quality helmets. All this carelessness and irresponsible activities play a dominant role in accidents that are leading to cause of death and disability. Helmets play a major role in protecting a human head injury in case of accidents. The purpose of this research is to create a smart and secure electronic helmet that plays a vital role in protecting human lives from accidents and this helmet help to send and monitor the information about the vehicle and also the person driving the vehicle. This research mainly focuses on indicating alerts to the driver about the surrounding vehicle movements while "changing the lane" and also helps to navigate the driver incorrect way for travelling. A high-speed motorist without a helmet has a very harmful impact that may lead to death. Helming will mitigate injury and save a life. The goal of this project is to increase motorcycle driver safety. If the limits of their speed are breached and cars reach the surrounding vehicle struck, motorcyclists shall be warned. The new cloud-based communications helmet program would transmit messages to the receiver material of the network. Many countries are implementing regulations that require the driver to wear a helmet while riding his motorcycle. Most accidents are caused by reckless driving, drunk or mobile phone use, while traffic laws and rules are violated. Many people lose their lives due to late notification of accident due to that the people are not able to monitor the accident area's precise GPS coordinates. The significant explanation that people get hurt in the head if they don't carry a cask while pushing the wheel. The Force Sensing Resistor (FSR) is used for measuring the driver's head and motorcycle acceleration. Just when the driver humps the helmet is the engine ignited. A LED will flash in the helmet while some obstacles or critical risk. Thus this research helps the researches for implementing and adopting the helmets in various aspects of security and protection of humans in future studies.

KEYWORDS: Smart Helmet, Gyroscope, Lane Changing, Signal Indication, Secure and Protective Helmet \& Internet of Things GPS Module.
\end{abstract}

Received: Jun 09, 2020; Accepted: Jun 29, 2020; Published: Jul 27, 2020; Paper Id.: IJMPERDJUN2020490

\section{INTRODUCTION}

The Project is mainly aimed at tracking, preventing and warning incidents [1]. This is achieved with the high-safety Smart Helmet device. Most accidents are the product of reckless travel, drunken driving, cell phones and road violations and laws. Often people are lost to their lives because of late accident reports that they were unable to trace the accident area's precise GPS location [2]. To solve these issues, we have initiated this research has been implemented. The main cause of head injuries to many while driving is due to helmet low qualities and also without wearing a helmet. The reason many riders don't wear a helmet is that they feel uncomfortable and suffocating while wearing it. In recent year's research have shown that wearing a helmet able to reduce the risk of a drastic brain 
injury and loss of lives because during an accident because of fall or collision of vehicles, most of the influence power is taken by the helmet, instead of your head and brain [3]. Two-wheelers require to take extra care and precautions to protect the body. The most prime place to begin by protecting the brain. The brain and head are most endangered to injury in a motorcycle accident. A motorcyclist wearing helmets grow the chance of survival remarkably over non-helmet wearers. Helmets are considered as a device secure head protector that has been developed over the years. Most of the countries and administration need to use secure headgear while during a motorcycle or bike. Various countries forcing the rules wear a helmet while driving vehicle especially concerned to two wheeler's rider need to when driving on their motorcycle, Malaysia is an instance of that kind of country. There has been many a trail to institute federal regulations of necessity helmets. Helmets had embedded with an electronic circuit which has been used in any kind of workplaces [4-6. In present research sensors and lane, changing plays major role actions like driving, riding, cycling, racing, a helmet with integrated sensors would provide maximum satisfaction and the chance to monitor the vehicle condition and surroundings condition simultaneously GPS receiver is generally isolated and unique, tiny chip (IC) when utilized in embedded applications. The chips are normally placed on aboard. When the chip is mechanized by voltage and receives the satellite signals, the chip emits a stream of NMEA (normally) encoded position data [8-9]. The current helmet also has features like GPS, GSM, alcohol detectors, airbags, camera, alarm and other facilities. therefore it has some downside, even though the helmet peaks in trend unexpectedly, the GSM can immediately send messages into emergency contacts, GPS displays only latitude and longitude but not visual locations [10]. The GPS is more convenient for drivers to contact immediately to the database contacts and alerting emergencies [11-12]. The primary objective of this research is to prevent accidents and to identify riders when they experience accidents.

\subsection{Arduino In Safety System}

Arduino is computer hardware, technology, venture, and developer community open-source that develops and produces one-board microcontrollers and microcontroller modules for creating electronic devices and objects in that control and senses the object in the physical world. Arduino board models use a range of micro and controller applications. The boards are supplied with sets of I / O pins that can be interfaced with specific extension boards (shields) and other circuit board [13].

\subsection{Alcohol Detecting Sensors Embedded In Helmet}

The sensor mounted in the mouth of the helmet interfaced with the IoT [14], The sensors senses whether the rider is intoxicated or not. Also allows the rider to begin the ignition when (BAC>0.03) the alcoholic level is disabled. If the rider is non-alcoholic, it is permitted to a safe drive.

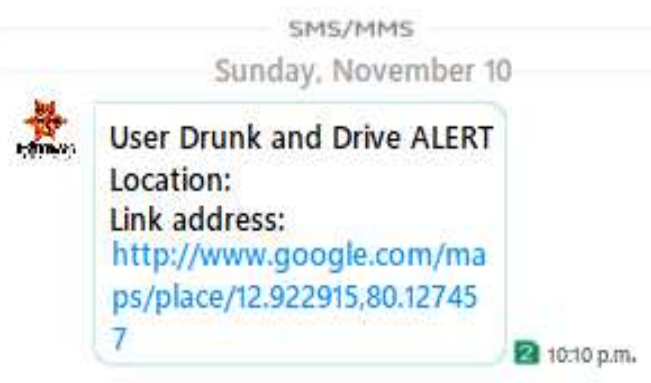

Figure 1: Sms-Alerting System Drunk \& Drive. 


\subsection{GSM and Clouds On Helmet}

If an incident happens in elevated pressure, the pressure sensor detects the pressure point; when it becomes greater than that amount, the device (GSM) intimates alerts and the system vibrates as it is known that the incident is happening. [15]. For the person as soon as possible to reach the hospital. It preserves the data in the cloud and keeps records. When the accident happens on several locations, the cloud gathers data from the GPS and GSM controller and then from the internet, which transmits messages to the ambulances, the police, the community and the local hospitals. To get the patient to the hospital as soon as possible. It stores data in the cloud and keeps records. So the government may display the accident area database and declare this region a vulnerable zone.

\subsection{GPS Module On Smart Helmet}

GPS only displays latitude and longitude with a precision of the accident zone. The GPS Mapping shares an exact zone of the accident that gives a clear view of saving the man. GPS controls the exact location of the crash. GPS sends information to cloud-based services, where the image is shot with a $360^{\circ}$ camcorder and accessed by a protection algorithm where the data are available only to emergency contacts. In Google map, a program was developed to indicate and display GPS navigation [16-17]. In Google map, a program was developed to indicate and display GPS navigation.

\subsection{Force Resistor Sensing (FSR)}

Sensing of force resistance (FSR) shown in the fig. structure. Force Resistance Sensing (FSR) 1 (a) must be installed inside the helmet as a tactile sensor to determine if the wearer is wearing his helmet. It consists of a low-resistance and increased pressure system for Polymer Thick Film (PTF) on the active surface[18].

\subsection{INTERNET OF THINGS}

The "Internet of Things" (IoT) is a network of virtual devices, automobiles, home appliances and other objects that have been built into computers, software, sensors, actuators and networking to communicate and exchange information. The IoT enables objects to be remotely sensed and managed through existing network infrastructures, creating opportunities to incorporate physically the environment more directly into computer systems and leading to increased performance, precision, and economic value as well as a reduced human response. The IoT platform is expanded with sensors and actuators and is an indicator of a broader variety of cyber-physical networks, including innovations like smart grids, electric power plants, smart houses, smart infrastructure and smart communities. These systems collect useful data from various existing technologies and then autonomously move data between other devices. The sensor is an instrument, a device, or a subsystem that aims to detect and send information to other electronics, often a software processor, for events or changes in their environment.

\subsection{IoT Based Smart Helmet}

The intelligent helmet is an innovative method of designing a helmet with the current trends using IoT technology for safety purposes. At present various countries have made it mandatory for riders and pillions to wear a helmet. Only if the driver removes the helmet and buckles the seat belt will the motorcycle alert the signal and the engine gets turned off. The risk of collisions will be minimized. If the driver is intoxicated, the alcohol detector will sense the alcohol level and prevent the rider from starting the car. SOS notifications will be sent to the person chosen by the user in the event of an emergency through IoT Applications. 


\section{i) Sensors}

A sensor is quite easy as light and complex as a device with other electronics. For everyday objects such as touchcontrolled controls, elevator buttons and lights, sensors are used, which damp or brighten when touching the unit.

\section{ii) Proposed System:}

The core element of the system is the Arduino board that manages and regulates all features carried out by the other devices. The element instructions are provided in the Arduino programming language.

Arduino is a physical programmable circuit board and a software module or IDE that operates on a device and which we use to write down and upload software code to the physical board. This model consists of the following components,

- MPU-6050 3-Axis Accelerometer and Gyro Sensor senses and tracks the co-ordinate system-based values and sends a signal on the monitor.

- The MQ3 Gas Sensor has high alcohol sensitivity to detect the concentration and sends a signal to stop the vehicle. Digital and analogue outputs in this unit.

\section{iii) Pressure Sensor}

Piezo electrical detector is used by the electrical charge to calculate variable changes including stress, temperature, acceleration and force of the dynamic motions.

\section{iv) Smart Alerting System}

According to Suhaib Muhammad [21] The utilization of cloud computing renders numerous benefits, When the rider wears a helmet and buckles it, the pressurized sensor sense and alarms to precautions of proper fit of a helmet. When a driver encounters an accident, SOS message will be sent. The software Ios, Sensors, Wi-fi and Cloud can be used. The Android app analyses the information and performs specific actions to the individual concerned over thecloud as shown in figure 1 $\&$ figure 2 .

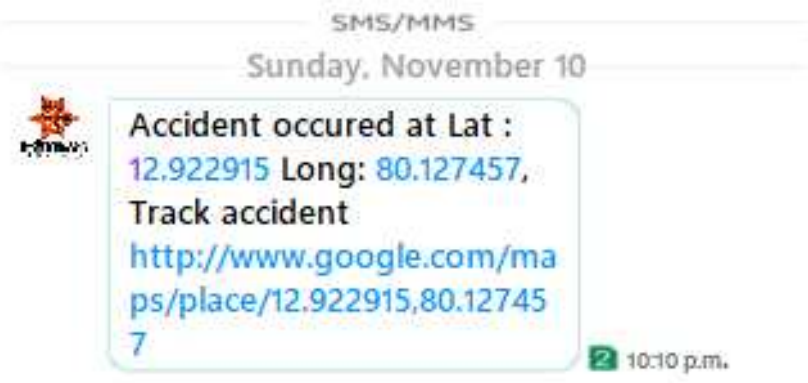

Figure 2: Sms-Alerting System During Accident Occurrence.

\section{v) Acceleration}

Acceleration can be stationary, like inertia, and dynamic acceleration can be rapid movement or vibration. Arduino is an open-source, software-and hardware-based electronics system. Boards of Arduino can read the input-a sensor signal, a hand on a key, message-and convert it into an output-by switching on a vehicle, turned on an LED or posting it digitally. This model fitted with the camera mounted on a helmet through which the incidences can be captured or stored in the data 
storage device.

\section{vi) Outcomes on Embedded API in Helmet}

To demonstrate the impact, we used the Google Map API as mentioned in the fig.3. Drivers can be cautious when driving the Google street view [17] from the camera is a snapshot of the road condition. On google road view there is a purple sign to signify the limit breaker. Such results reveal that our approach works with the best results.

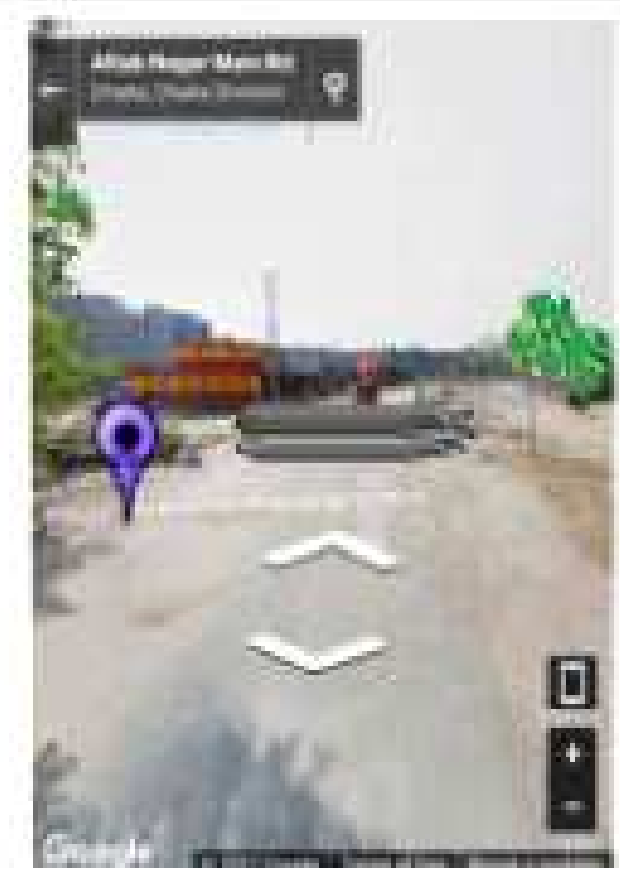

Figure 3: Google Street Visible through SMART Helmet Monitor System.

\section{vii) Detecting Bumps, And Other Obstacles}

Suhaib Muhammad [18] established a model how to detect the obstacle and deal with the conflicts, The traffic crash cannot be wiped away, but the state of the path towards the car's driver can be illustrated. In this report, to ensure a safe drive by implementing IoT, we propose a design that connects that device with another device to help prevent road accidents. Using real-time deployment capabilities in the Android software, design outputs (longitude, latitude and speed, acceleration information for vehicles) are collected in this situation. The design consists of two computer technology. The primary motivation is to provide an in-house traffic control network in real-time, ensuring safe, accident-free and fast driving.

\section{viii) Impacts of Velocity of a Vehicle Over Time}

The frequency of the vehicle is defined through the approached design and research as compared below in Table.1. Using IoT and accelerometer sensors. The drastic variance on the velocity of the vehicle overtime period can be observed. This condition suggests that in these places there are potholes and speed-breakers / bumps.

Table 1: A Comparison Study on Existing and Advanced SMART Helmet

\begin{tabular}{|l|l|}
\hline \multicolumn{1}{|c|}{$\begin{array}{c}\text { Existing Smart } \\
\text { Helmets Features. }\end{array}$} & \multicolumn{1}{c|}{ Lane Changing signal Assist Helmet Features. } \\
\hline $\begin{array}{l}\text { Inbuilt cooling fan to } \\
\text { keep the heat away from } \\
\text { the tight space on the } \\
\text { Head. }\end{array}$ & $\begin{array}{l}\text { 1) We have Lane changing Alert System which assists the driver of an upcoming } \\
\text { vehicle from the back. }\end{array}$ \\
\hline
\end{tabular}




\begin{tabular}{|l|l|}
\hline $\begin{array}{l}\text { Inbuilt Bluetooth system } \\
\text { to connect devices } \\
\text { wirelessly. }\end{array}$ & $\begin{array}{l}\text { 2) We have Alcohol Detection Sensor which Does not allow the Connected bike to start } \\
\text { so that drink and drive can be avoided. }\end{array}$ \\
\hline $\begin{array}{l}\text { Accident alert system to } \\
\text { send the signal to the } \\
\text { selected phone numbers. }\end{array}$ & $\begin{array}{l}\text { 3) We have Ultrasonic sensor to sense that the rear vehicle has maintained a safe } \\
\text { distance or else it can be alarmed. }\end{array}$ \\
\hline $\begin{array}{l}\text { Cell phone charging } \\
\text { with the solar power to } \\
\text { avoid charge running } \\
\text { out. }\end{array}$ & $\begin{array}{l}\text { 4) We use LED's and buzzer for better alarm detection during the night time as well as } \\
\text { during the heavy noise or crowded places. }\end{array}$ \\
\hline $\begin{array}{l}\text { Acceleration and } \\
\begin{array}{l}\text { Gyroscopic Sensor for } \\
\text { Stability and Impact } \\
\text { Alert. }\end{array}\end{array}$ & $\begin{array}{l}\text { 5) Additional to all above we also have the normal smart helmet features like location } \\
\text { tracking and alarming, acceleration and gyroscopic sensors etc. }\end{array}$ \\
\hline
\end{tabular}

\section{EXPERIMENTAL SETUP}

In this paper, the proposed Advanced SMART HELMET for Daily Applications of Motor-Drivers and The best safety assured helmet has been developed using IoT, Arduino programming. This helmet incorporated with advanced safety alerting technology, Drunk \& Drive, i.e., less safety higher allocation of alerting technology has been followed up in the helmet. This helmet had designed with monitoring, the gyroscope of balancing, alcohol detecting, distance detecting, helmet lock connecting and disconnecting and other specifications with advanced technology had been implemented. The proposed technology represented in schematic representation below fig.4. This research brings advanced technology to all people to afford and drive safety lives.

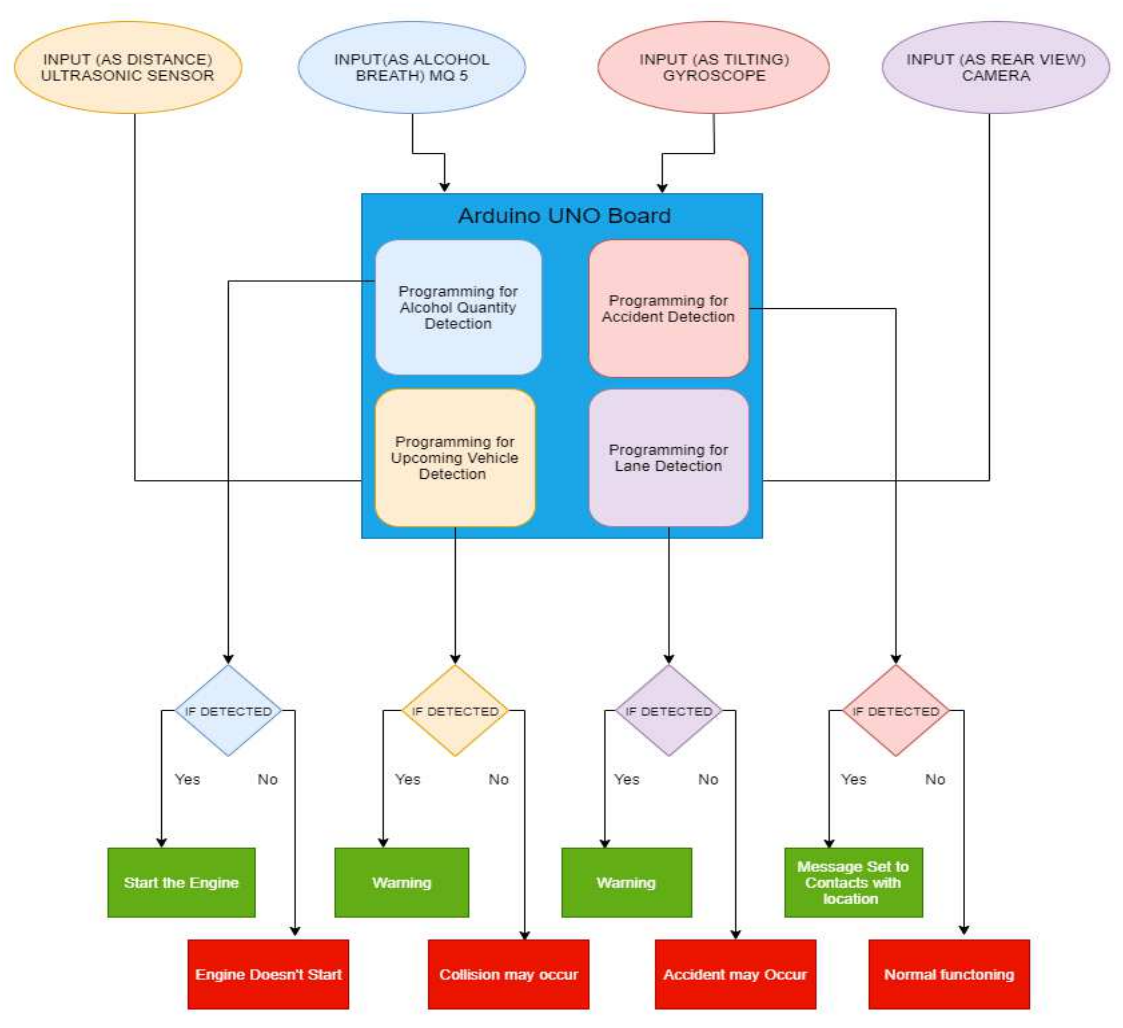

Figure 4: A Flow Chart: IoT_Based Detecting Technology Schematic Representation. 

Assist Technology with Smart Helmet

An Aurdino- Program Complied for SMART HELMET

ii) Complied Result

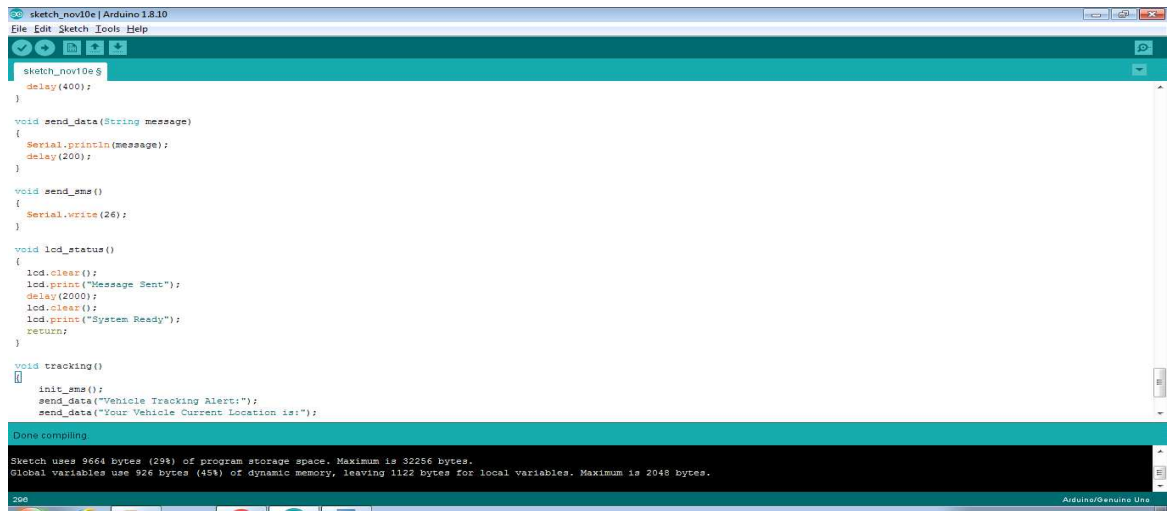

Figure 5: An Aurdino Program Compiling.

iii) Working Model
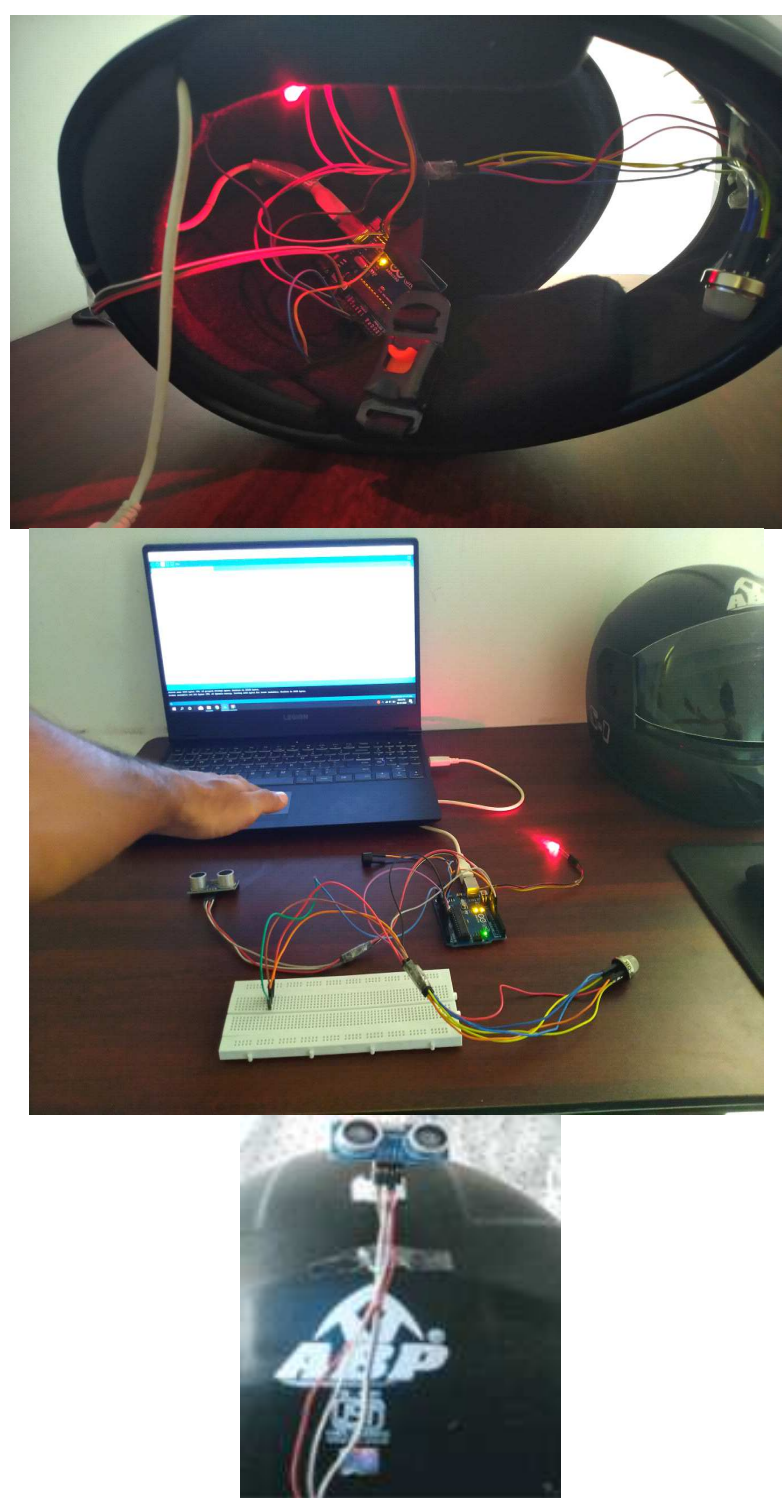

Figure 6: Proposed Working Model. 


\section{DISCUSSIONS}

- The Purpose of this above research is to increase the Biker road safety as well as provides him with the assist and control of different driving parameters using simple Sensors, Microcontroller (Adriano Uno), Jumper Wires, Programming's etc.

- This Research can be further Updated in future with many other IoT based Technologies making the TwoWheeler Driving more Safer and Easier till then we need to focus on minimising the accidents on the roads and how to overcome from it.

- Finally, with the Overall research with our working model it can be concluded that this Smart Assist Helmet will be very useful, Cheap and easy to use as compare to other normal helmets present in the market.

- Regardless of the denominator is used (residents, registration of motorbikes and motorbike crashes), States that have complete helmet laws were generally at lower rates of death — associated with accidents than states that have no such legislation, even when stratified by area.

- However, the total motorcycle mortality among law groups was similar.

- The Registers or crashes have the fivefold-to-six-fold risk of head injury to motorcyclists who died in crashes compared to people who died with other motorcycles and other accident statistics.

- Thus, This Research had considered all these above-mentioned problems and proposed a Modern and Smart Helmet for the safety of every individual.

\section{CONCLUSIONS}

The foregoing conclusions are focused on: in this new field study, many scholars have taken careful note of the above inquiries and have explained the foregoing: The following:

The intelligent cask is a sophisticated and versatile product which can be built and run at low cost which does not undermine the safety mechanism. It also offers several effective advantages over established crash monitoring and alert networks which rely heavily on data information from cellular devices of drivers. Our proposed design would warn users and safely avoid injuries, intoxicated or travel through pace. In particular, it will integrate a cost-effective camera costing a few bucks with a safety device such as the helmet and incorporate the image processor with its innovative algorithm. In this paper, a new approach is presented in the form of an intelligent helmet that incorporates video processing to improvise the protection of motorcyclists. The paper provides a new algorithm for detecting vehicles from the rear end, the side edge of the bike as well as a methodology for warning the driver of their distance. Further protection, particularly while the driver turns and also avoiding false alarms due to stationary vehicles was also taken care.

\section{REFERENCES}

1. M. Fogue, P. Garrido, F. Martinez, J. Cano, C. Calafate and P. Manzoni 2012, "Automatic Accident Detection: Assistance Through Communication Technologies and Vehicles", IEEE Veh. Technol. Mag., vol. 7, no. 3, pp. 90-100

2. J. White, C. Thompson, H. Turner, B. Dougherty, and D. C. Schmidt 2011, "WreckWatch: Automatic Traffic Accident Detection and Notification with Smartphones," Mob. Netw. Appl., vol. 16, no. 3, pp. 285-303. 
3. Yilin Zhao, "Mobile phone location determination and its impact on intelligent transportation systems 2000", IEEE Trans. Intell. Transport. Syst., vol. 1, no. 1, pp. 55-64.

4. M. Fogue, P. Garrido, F. Martinez, J.-C. Cano, C. Calafate, and P. Manzoni 2008, "Automatic Accident Detection: Assistance Through Communication Technologies and Vehicles," IEEE Veh. Technol. Mag., vol. 7, no. 3, pp. 90-100,

5. H. Hartenstein and K. Laberteaux 2016, “'A tutorial survey on vehicular ad hoc networks,” IEEE Commun. Mag., vol. 46, no. 6, pp. 164-171, June 2008 IEEE Standard for Wireless Access in Vehicular Environments(WAVE)- Identifier Allocations, IEEE Standard 1609.12.

6. Elashkar, Magdy Ali. "the Use of Simulation Techniques in the Development of Non-Technical Skills for Marine Officers." International Journal of General Engineering and Technology (IJGET) 5.5 (2016): 19-26.

7. Prudhvi Raj R, Sri Krishna Kanth, Bhargav Aditya Bharath K 2014, "Smart-tec Helmet" Electrical and Electronics Engineering, GITAM University, Rushikonda, Visakhapatnam, India. Advance in Electronic and Electric Engineering 4: 493498.

8. Behr, C.J., Kumar, A., Hancke, G.P 2016, “ A Smart Helmet for Air Quality and Hazardous Event Detection for the Mining Industry” Proceedings of the IEEE International Conference on Industrial Technology 2016- May,7475079, pp. 2026-2031

9. SreenithyChandran, SnehaChandrasekar, $N$ Edna Elizabeth "Konnect: An Internet of Things(IoT) based smart helmet for accident detection and notification” 2016 IEEE Annual India Conference (INDICON)

10. Xu, You Cheng, and Xin Yuan Liu."Recent progress in double helix conjecture." Int. J. Appl. Nat. Sci 7 (2018): 85-100.

11. Rashmi Vashisth, Sanchit Gupta, Aditya Jain, Sarthak Gupta, Sahil, Prashant Rana "Implementation and analysis of smart helmet” 2017 4th International Conference on Signal Processing, Computing and Control (ISPCC)

12. D. Selvathi, P. Pavithra, T. Preethi “Intelligent Transportation System for Accident Prevention and Detection” 2017 International Conference on Intelligent Computing and Control Systems (ICICCS)

13. Archana D, Boomija G, Manisha J, Kalaiselvi V. K. G. "Mission On! Innovations in Bike Systems to Provide a Safe Ride Based on IoT” 2017 2nd International Conference on Computing and Communications Technologies (ICCCT)

14. SayanTapadar, Shinjini Ray; Himadri, NathSaha; Arnab, Kumar Saha, Robin Karlose "Accident and alcohol detection in Bluetooth enabled smart helmets for motorbikes" 2018 IEEE 8th Annual Computing and Communication Workshop and Conference $(C C W C)$

15. MohdKhairul, AfiqMohdRasli, Nina KorlinaMadzhi, Juliana Johari, "Smart Helmet with Sensors for Accident Prevention", Faculty of Electrical Engineering University Technology MARA40450 Shah Alam Selangor

16. M. Khiyal, A. Khan, E. Shehzadi 2009, "SMS Based Wireless Home Appliance Control System (HACS) for Automating Appliances and Security", Issues in Informing Science and Information Technology, vol. 6, pp. 887-894.

17. Cheng Yuan Tang, Yi-Ping Hung, Sheng-Wen Shin, and Zen Chen 1999, "A 3D Feature-Based Tracker for Multiple Object Tracking," Proc.Natl. Sci. Counc. ROA(A) vol. 23, No. 1, pp. 151-168.

18. Davlechina, Anna P., et al. "Methodology of vehicle operational loads assessment during vehicle development process for further chassis and body-in-white strength and durability analysis." International Journal of Mechanical and Production Engineering Research and Development 8 (2018): 1415-1424.

19. Seok Ki Hong, and Chan Gook Park 2005, "A 3D Motion and Structure Estimation Algorithm for Optical Head Tracker System, " AIAA Conference of Guidance, Navigation and Control, San Francisco, CA, AIAA paper 2005-5964, August 15-18 
20. Foxlin,E., Altshuler, Y, Naimark, L. and Harrington, M, 2004, "Flight Tracker: A Novel Optical/Inertial Tracker for Cockpit Enhanced Vision," IEEE/ACM International Symposium on Mixed and Augmented Reality (ISMAR 2004), November 2-5.

21. Suhaib, Muhammad (2019), Conflicts Identification among Stakeholders in Goal Oriented Requirements Engineering Process. International Journal of Innovative Technology and Exploring Engineering (IJITEE) 2278-3075, Volume-8 Issue-12, pp. 4926-4930.

22. Srivastava, R. K., and A. T. U. L. Natu. "A 7PS Model of Retail Patronage: A Meta-Synthesis of Contemporary Research." International Journal of Retail Management and Research (IJRMR) 4.1 (2014): 1-22.

23. Suhaib, Muhammad (2019), Effects of Visual and Auditory Response Times in Males and Females by using Tactile and Mouse on Web Based Environment. International Journal of Recent Technology and Engineering (IJRTE) ISSN: 2277-3878, Volume8 Issue-3, pp.6458-6464.

24. Suhaib, Muhammad (2020), Investigation and Analysis of the Requirement Engineering in Software Development Process and its Systematic Requirements Elicitation Approach. International Journal of Scientific and Technology Research, ISSN: 22778616, Volume-9 Issue-4, pp. 2723-2726

25. Suhaib, Muhammad (2020), Usage of cloud computing technology and challenges in Japanese higher educational institutes. International Journal of Scientific and Technology Research, ISSN: 2277-8616, Volume-9 Issue-4, pp. 2727-2733. 